\title{
Effect of saphenous vein diameter and reflux time on stump length after cyanoacrylate closure
}

\author{
JEONGIN KIM, JIN HYUN JOH and HO-CHUL PARK \\ Department of Surgery, Kyung Hee University Hospital at Gangdong, \\ Kyung Hee University School of Medicine, Seoul 05278, Republic of Korea
}

Received August 15, 2017; Accepted April 5, 2019

DOI: $10.3892 /$ etm.2019.7758

\begin{abstract}
Cyanoacrylate closure (CAC) has recently been introduced for the treatment of incompetent saphenous veins. The purpose of the present study is to investigate the correlation of the saphenous vein diameter and reflux time (RT) with the stump length after CAC. A retrospective review was performed using prospectively collected data of CAC patients. The pre-operative saphenous vein diameter and RT were measured. The stump length was measured immediately after the procedure and at 1 week. Pearson's correlation analysis was applied to determine the correlation between the saphenous vein diameter or RT and stump length. A total of 32 saphenous veins were closed in 21 patients, 15 of whom were female. The mean age was 56.9 \pm 12.6 years (range, 31-73 years). Complete closure was achieved in all patients. The pre-operative mean diameter was $7.0 \pm 2.2 \mathrm{~mm}$. The mean stump lengths were $26.1 \pm 10.2$ and $28.1 \pm 13.6 \mathrm{~mm}$ on post-operative days 0 and 7 , respectively $(\mathrm{P}=0.002)$. The Pearson coefficients for the correlation between the saphenous vein diameter and stump length on post-operative days 0 and 7 were $0.528(\mathrm{P}=0.005)$ and $0.177(\mathrm{P}=0.430)$, respectively. Furthermore, the Pearson coefficients for the correlation between the RT and stump length on post-operative days 0 and 7 were $-0.215(\mathrm{P}=0.282)$ and $0.019(\mathrm{P}=0.938)$, respectively. In conclusion, CAC is effective modality for the treatment of saphenous vein insufficiency. The stump length increased with the diameter of the saphenous veins, while the RT had no marked effect on the stump length. Therefore, the glue injection should be initiated from the instructed position to avoid glue extension into deep veins and to prevent elongating the stump length.
\end{abstract}

Correspondence to: Dr Jin Hyun Joh, Department of Surgery, Kyung Hee University Hospital at Gangdong, Kyung Hee University School of Medicine, 892 Dongnam-ro, Gangdong-gu, Seoul 05278, Republic of Korea

E-mail: jhjoh@khu.ac.kr

Key words: venous insufficiency, varicose vein, saphenous vein, cyanoacrylate

\section{Introduction}

Varicose veins are common; in Western countries, an estimated $23 \%$ of adults have varicose veins and $6 \%$ have more advanced chronic venous disease, including skin changes and healed or active venous ulcers (1). These have a significant impact on healthcare resources. It has been estimated that 1-3\% of total healthcare expenditures are linked to venous disorders (2).

Open surgical treatment with ligation and stripping of the saphenous vein, combined with excision of large varicosities, has been the standard of care for numerous years. Endovenous thermal radiofrequency ablation (RFA) and endovenous laser ablation are safe and effective alternatives, with high long-term target vein closure rates. Although the two techniques have gained broad acceptance in numerous countries, a major disadvantage is the requirement for tumescent anesthesia to avoid thermal injury to surrounding structures (3).

Cyanoacrylate closure (CAC) using the VenaSeal ${ }^{\mathrm{TM}}$ Closure System (Medtronic) for varicose veins has recently been introduced for the treatment of incompetent saphenous veins (4-6). Although preliminary studies have been limited to moderate-sized great saphenous veins (GSVs), larger diameters of up to $20 \mathrm{~mm}$ have been included in certain studies (7). The purpose of the present study was to investigate the correlation of the saphenous vein diameter or reflux time (RT) with the stump length after CAC.

\section{Materials and methods}

Data collection. A retrospective review was performed of prospectively collected data of patients with varicose vein who underwent CAC at Kyung Hee University Hospital at Gangdong (Seoul, Korea) from November 2016 to February 2017. A detailed review of the medical history and physical examination were performed at the initial visit to the outpatient department.

Measurement of vein diameter and reflux time. Colorized duplex scanning was performed prior to the procedure. The maximum diameter of the GSV and the small saphenous vein (SSV) were measured in the standing position using a tilt table. With gray-scale imaging, the inner anechoic diameter of the GSV was measured from the saphenofemoral junction (SFJ) to $5 \mathrm{~cm}$ distal to the junction. The SSV diameter was measured 
in the same manner from the saphenopopliteal junction (SPJ) to $5 \mathrm{~cm}$ distal to the junction. If a cranial extension of the SSV was present, the diameter was measured at $5 \mathrm{~cm}$ distal to the connection with the deep venous system. If no definite connections with the deep venous system were present, the diameter was measured at the site where the SSV was in contact with the fascia. The largest diameter was selected to analyze the correlation between diameter and stump length. After measurement of the diameter, the RT at the SFJ, SPJ and truncal vein in response to a Valsalva maneuver and/or manual distal compression followed by release in standing position were evaluated. Saphenous reflux was defined as RT of $>500$ msec.

Surgical procedure. Indications for CAC were clinical grade C2-C6 (8) and symptoms or cosmetic concerns. The CAC procedure was performed under local anesthesia with or without sedation in the operating room. An 18-G angio catheter was inserted into the saphenous vein under ultrasound guidance. Access sites were selected around the knee joint for the GSV and the lower calf for the SSV. A 0.035-inch guidewire was inserted into the deep vein through the SFJ or SPJ. This was followed by positioning of an introducer sheath up to the junction. Subsequently, the dilator and guidewire were removed. After flushing the sheath, it was gently pulled back $5 \mathrm{~cm}$ from the junction under ultrasound guidance. A prepared catheter loaded with cyanoacrylate glue was introduced through the sheath. The sheath and catheter were then connected. The tip of the catheter was positioned $5 \mathrm{~cm}$ from the junction. With the catheter in place and secured at this level, an ultrasound probe was positioned $2 \mathrm{~cm}$ proximal to the tip of the catheter. Subsequently, $0.1 \mathrm{ml}$ of glue was injected by pressing the trigger. The catheter was pulled back $1 \mathrm{~cm}$ distally and another $0.1 \mathrm{ml}$ of glue was injected. The catheter was then pulled back $3 \mathrm{~cm}$ distally. The injected segment was compressed for $3 \mathrm{~min}$ with the right hand. After successful closure of this segment, the catheter tip was checked with an ultrasound probe. Subsequently, $0.1 \mathrm{ml}$ of glue was injected and the catheter was pulled back $3 \mathrm{~cm}$ distally. The injected segment was again compressed for $30 \mathrm{sec}$ in the same manner as above. This process was repeated until approaching the skin surface to $5 \mathrm{~cm}$ below and the catheter was then removed. After completion of the procedure, ultrasound examination was performed for evaluation of complete closure of the saphenous vein and the presence of glue extension into the common femoral vein or popliteal vein. The pain score was evaluated immediately after the procedure by using the visual analog scale (VAS) (7).

Post-operative management. After completion of the procedure, concomitant phlebectomy was performed. All wounds were closed with skin adhesive. The treated legs were dressed using a $10 \mathrm{~cm}$ wide, short-stretch cohesive elastic bandage (Karl Otto Braun $\mathrm{GmbH} \& \mathrm{Co}$ ) if required. The elastic bandage was replaced with thigh-length compression stockings after $24 \mathrm{~h}$. This was then worn for up to 7 days. Patients were discharged at a minimum of $6 \mathrm{~h}$ post-operatively after full recovery and confirmation of no procedure-associated side effects. The patients were prescribed analgesics only when required and returned to work when they were comfortable.

Follow-up. Patients were followed up at 1 week and at 3 months after the CAC procedure. At all subsequent visits, the patients were clinically examined and subjected to duplex ultrasound scanning. At 1 week, duplex scanning was performed to confirm saphenous vein closure and to detect any complications, including deep vein thrombosis, endovenous glue-induced thrombosis (EGIT), or any complications associated with the procedure. The pain score was again measured by using the VAS.

Measurement of stump length. On Doppler ultrasound, the stump length was measured from the SFJ or SPJ to the leading point of closure at the end of the procedure and on post-operative day 7, as showcased in Fig. 1. The correlation between the pre-operative saphenous vein diameter or RT and stump length was assessed.

Statistical analysis. For statistical evaluation, a Student's t-test and Pearson correlation analysis were performed using SPSS statistics version 22.0 (IBM Corp). $\mathrm{P}<0.05$ was considered to indicate statistical significance.

\section{Results}

Demographics. During the study period, 21 consecutive patients (28 limbs) were subjected to the CAC procedure. Patient demographics are provided in Table I. The mean age was $56.9 \pm 12.6$ years (range, $31-73$ years), and the cohort included 15 females and 6 males. The most common symptom indication for this procedure was discomfort, followed by heaviness, night cramping, pain and swelling. Saphenous veins with pathologic reflux were treated simultaneously. CAC was performed on 1 truncal vein in 12 patients (57.1\%), 2 truncal veins in 8 patients (38.1\%) and 4 truncal veins in 1 patient $(4.8 \%)$.

Outcomes. Complete closure, defined as Doppler ultrasound examination indicating closure along the entire treated target vein segment, with no discrete segments of patency located $<5 \mathrm{~cm}$ away from the junction, was achieved in all patients. In 1 patient, a specimen of the treated saphenous vein was obtained. After treatment, the superficially-located GSV in the knee area was revealed. Therefore, the GSV was removed. Complete closure was confirmed as presented in Fig. 2. The VAS pain scores were 2.59 and 0.32 immediately after the procedure and on post-operative day 7 , respectively $(\mathrm{P}<0.0001)$. There was no EGIT. Phlebitis occurred in 1 patient on day 10 after the procedure, and was resolved with the use of analgesics and ibuprofen.

Correlation analysis. There was a positive correlation between saphenous vein diameter and stump length immediately after the procedure (Pearson's coefficient, 0.528; $\mathrm{P}=0.005$ ), as presented in Fig. 3. However, there was no correlation on post-operative day 7 (Pearson's coefficient, 0.177; $\mathrm{P}=0.430$ ). Furthermore, there was no correlation between the saphenous vein RT and stump length immediately after the procedure (Pearson's coefficient, 0.215; $\mathrm{P}=0.282$ ) and on post-operative 
day 7 (Pearson's coefficient, 0.019; $\mathrm{P}=0.938$ ), as presented in Fig. 4.

\section{Discussion}

The present study demonstrates that CAC is effective and safe for the treatment of saphenous vein insufficiency. Complete occlusion of the treated segments was achieved in all patients. There were no obvious side effects, except for phlebitis in 1 patient. The results of the present study were in correspondence with those of previous ones. A European multicenter cohort study reported a cumulative 12-month free from recanalization rate of $92.9 \%$ (9). The first randomized trial comparing CAC and RFA for incompetent GSVs determined a 3-month closure rate of $99 \%$ for the CAC group (4).

Certain studies on the saphenous vein stump after endovenous treatment suggest that its presence may contribute to the formation of late inguinal varicose vein recurrence. Geier et al (10) reported that a long residual saphenofemoral stump was present in approximately two-thirds of patients with symptomatic groin recurrences. Therefore, the stump length should be kept as short as possible. Several factors may affect the stump length after CAC, including the initial position of the delivery catheter tip, as well as the saphenous vein diameter, RT and peak RT. The saphenous vein diameter and RT may be the major factor affecting the stump length. In the present study, a positive correlation between saphenous vein diameter and stump length was identified immediately after the procedure (Pearson's coefficient, 0.528; $\mathrm{P}=0.005$ ). The stump length increased with the diameter of the saphenous vein. No correlation was identified between the saphenous vein $\mathrm{RT}$ and stump length immediately after the procedure (Pearson's coefficient, $0.215 ; \mathrm{P}=0.282$ ) and on post-operative day 7 (Pearson's coefficient, $0.019 ; \mathrm{P}=0.938)$. The initial position of the catheter tip was $5 \mathrm{~cm}$ distal to the junction in all patients.

In the cohort of the present study, none of the patients developed deep vein thrombosis after the procedure. Glue extension into a deep vein is a possible complication. EGIT is similar to endovenous heat-induced thrombosis after RFA or laser ablation (11-13). In the WAVES study, 1 out of 50 patients had thrombus extension that protruded $2 \mathrm{~mm}$ into the SFJ on post-operative day 7 as identified on duplex evaluation (7). Chan et al (14) reported minimal extension into the deep veins in 2 of 108 legs $(1.9 \%)$. The risk factors for EGIT remain elusive. Theoretically, the glue may extend closer to the junction in smaller-diameter of saphenous veins. Therefore, secure compression of the proximal segment with the ultrasound probe is required if the patient has a smaller-diameter of saphenous vein.

Phlebitis was reported to be the most common complication of this procedure (4), and this occurred somewhat more commonly than in RFA-treated subjects ( 20 vs. $14 \%$; $\mathrm{P}=0.36$ ). Almeida et al (15) reported a lower rate of phlebitis of $15.8 \%$. Sensitization to cyanoacrylate after dermal wound repair or occupational contact has been described (16). Eosinophilic inflammation was reported in a small proportion after embolization of intracranial arteriovenous malformations (17). A lower incidence of phlebitis was reported by Tekin et al (18) (3.2\%), but this may have been due to a shorter follow-up period. Koramaz et al (19) reported the lowest rate of phlebitis (2.1\%).
Table I. Demographics and clinicopathological characteristics of the patients of the present study $(n=21)$.

\begin{tabular}{|c|c|}
\hline Parameter & Value \\
\hline Age (years) & $56.9 \pm 12.6(31-73)$ \\
\hline \multicolumn{2}{|l|}{ Sex } \\
\hline Male & $6(28.6 \%)$ \\
\hline Female & $15(71.4 \%)$ \\
\hline \multicolumn{2}{|l|}{ Indication for treatment } \\
\hline Discomfort & $19(90.5)$ \\
\hline Heaviness & $18(85.7)$ \\
\hline Night cramping & $17(81.0)$ \\
\hline Itching & $3(14.3)$ \\
\hline Pain & $2(9.5)$ \\
\hline Swelling & $1(4.8)$ \\
\hline \multicolumn{2}{|l|}{ Limbs } \\
\hline Total & 28 \\
\hline Right & $5(23.8)$ \\
\hline Left & $9(42.9)$ \\
\hline Bilateral & $7(33.3)$ \\
\hline \multicolumn{2}{|l|}{ Treated truncal veins with one session } \\
\hline Total & 32 \\
\hline 1 & $12(57.1)$ \\
\hline 2 & $8(38.1)$ \\
\hline 3 & $0(0.0)$ \\
\hline 4 & $1(4.8)$ \\
\hline Diameter of saphenous vein (mm) & $7.0 \pm 2.2(1.7-12.3)$ \\
\hline \multicolumn{2}{|l|}{ Stump length (mm) } \\
\hline Immediately after procedure & $26.1 \pm 10.2(11.5-43.2)$ \\
\hline At 7 days post-surgery & $28.1 \pm 13.6(6.4-56.2)$ \\
\hline
\end{tabular}

Values are expressed as the mean \pm standard deviation (range) or $\mathrm{n}(\%)$.

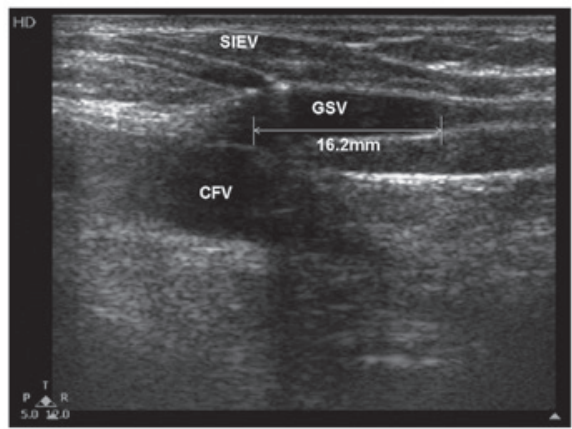

Figure 1. Measurement of the stump length with Doppler ultrasound at day 0 . The stump length was measured as the length from the saphenofemoral or saphenopopliteal junction to the leading point of closure. In the representative case provided, the stump length was measured as $16.2 \mathrm{~mm}$. CFV, common femoral vein; GSV, great saphenous vein; SIEV, superficial inferior epigastric vein.

The authors suggested that the lower incidence of phlebitis compared with that in other studies was due to continuous injection and lower viscosity of cyanoacrylate. In the present study, phlebitis occurred in 1 patient $(4.7 \%)$ after CAC was performed 

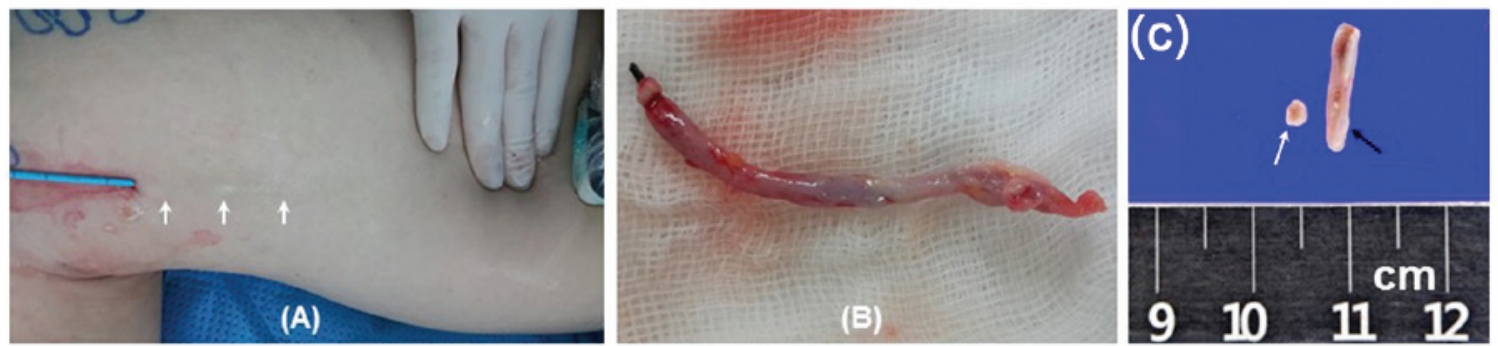

Figure 2. (A and B) The specimen was obtained by excision of the shallowly positioned saphenous vein after cyanoacrylate closure (arrows). (C) The transversely (white arrow) and longitudinally (black arrow) cut surface indicates complete closure of the saphenous vein.

A

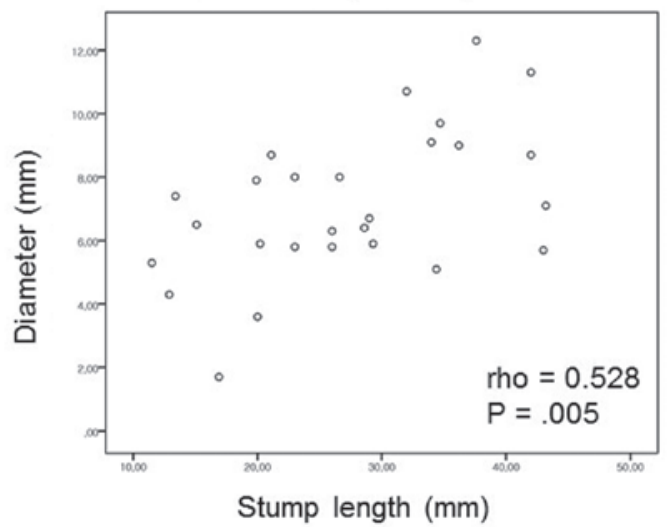

B

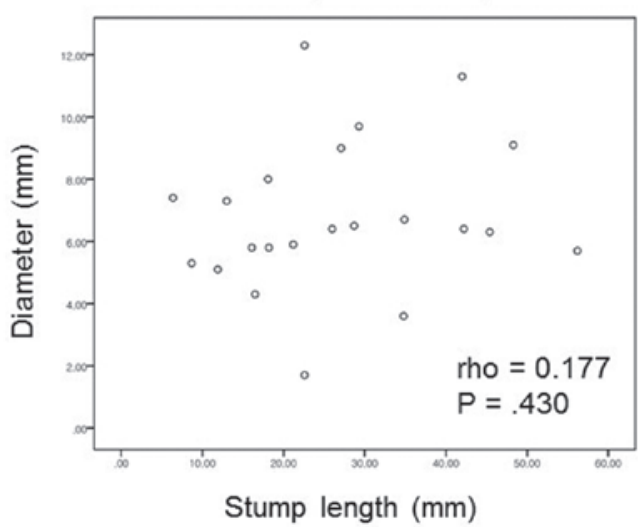

Figure 3. Correlation between pre-operative venous diameter and stump length. (A) A positive correlation between the saphenous diameter and stump length was determined immediately after the operation (Pearson correlation coefficient, $0.528 ; \mathrm{P}=0.005$ ). (B) However, there was no correlation on post-operative day 7 (Pearson correlation coefficient, $0.177 ; \mathrm{P}=0.430$ ).
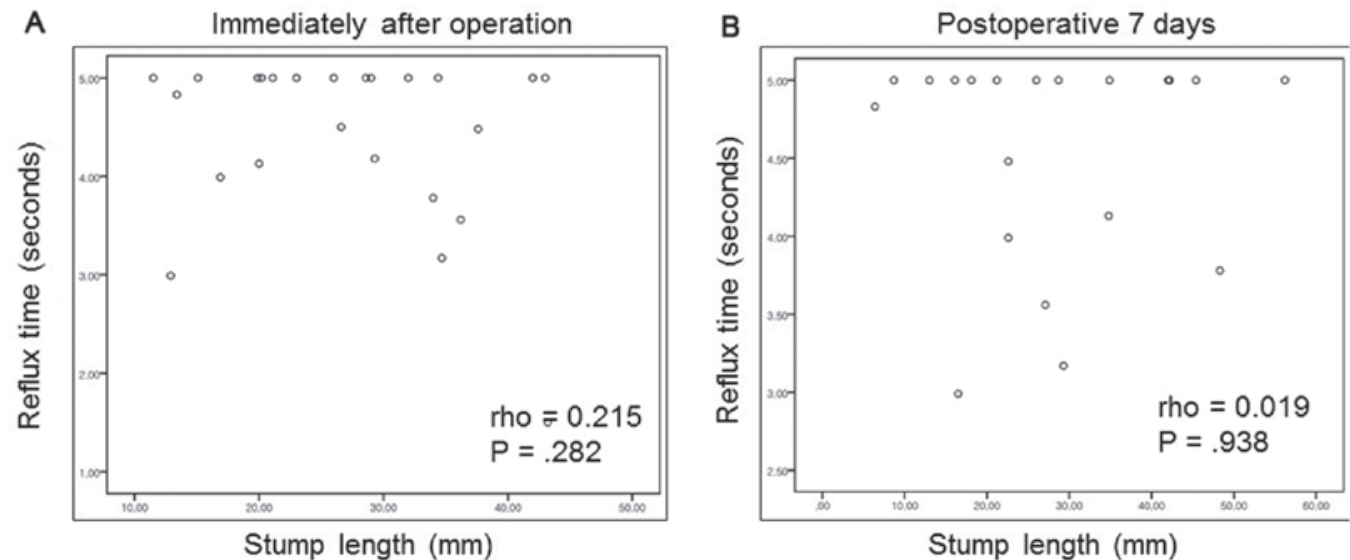

Figure 4. Correlation between reflux time and stump length. There was no correlation between the reflux time of the saphenous vein and stump length immediately (A) after the operation (Pearson correlation coefficient, $0.215 ; \mathrm{P}=0.282$ ) and (B) on post-operative day 7 (Pearson correlation coefficient, 0.019 ; $\mathrm{P}=0.938)$.

for bilateral GSV reflux. An access was made below the knee GSV segment in both legs. In all other patients, however, venous access was made above the knee joint. Mechanical stress due to knee joint movement may have been a cause of phlebitis.

The primary advantage of CAC is that it does not require the injection of perivenous tumescent solution. Thermal RFA and laser technology necessitate the placement of perivenous tumescent fluid to dissipate the heat. This is time-consuming to administer and requires several painful percutaneous injections. Another advantage is less bruising than with thermal technologies (4).

The present study has several limitations, including the single-center study design, the retrospective nature of the database analysis and the relatively small number of patients. Further and bigger-sized studies are required to confirm the results of the present study. 
In conclusion, $\mathrm{CAC}$ is effective for the treatment of saphenous vein insufficiency. The stump length increased with the diameter of the saphenous veins. However, the RT was not correlated with the stump length after CAC.

\section{Acknowledgements}

Not applicable.

\section{Funding}

No was funding received.

\section{Availability of data and materials}

The datasets used and/or analyzed are available from the corresponding author on reasonable request.

\section{Authors' contributions}

JK collected the data, wrote the manuscript and performed statistical analysis. JJ conceived and designed the current study, analyzed and interpreted the data, and takes responsibility for the manuscript. HP acquired the data and revised the manuscript.

\section{Ethics approval and consent to participate}

Not required due to retrospective nature of the study.

\section{Patient consent for publication}

The respective patient provided written informed consent regarding the publication of their images.

\section{Competing interests}

The authors declare that they have no competing interests.

\section{References}

1. Kaplan RM, Criqui MH, Denenberg JO, Bergan J and Fronek A Quality of life in patients with chronic venous disease: San Diego population study. J Vasc Surg 37: 1047-1053, 2003.

2. Lafuma A, Fagnani F, Peltier-Pujol F and Rauss A: Venous disease in France: An unrecognized public health problem. J Mal Vasc 19: 185-189, 1994.

3. van den Bos R, Arends L, Kockaert M, Neumann M and Nijsten T: Endovenous therapies of lower extremity varicosities: A meta-analysis. J Vasc Surg 49: 230-239, 2009.

4. Morrison N, Gibson K, McEnroe S, Goldman M, King T, Weiss R, Cher D and Jones A: Randomized trial comparing cyanoacrylate embolization and radiofrequency ablation for incompetent great saphenous veins (VeClose). J Vasc Surg 61: 985-994, 2015.
5. Kolluri R, Gibson K, Cher D, Madsen M, Weiss R and Morrison N: Roll-in phase analysis of clinical study of cyanoacrylate closure for incompetent great saphenous veins. J Vasc Surg Venous Lymphat Disor 4: 407-415, 2016.

6. Chan YC, Law Y, Cheung GC, Ting AC and Cheng SW: Cyanoacrylate glue used to treat great saphenous reflux: Measures of outcome. Phlebology 32: 99-106, 2017.

7. Gibson K and Ferris B: Cyanoacrylate closure of incompetent great, small and accessory saphenous veins without the use of post-procedure compression: Initial outcomes of a post-market evaluation of the VenaSeal System (the WAVES Study). Vascular 25: 149-156, 2017.

8. Gloviczki P, Comerota AJ, Dalsing MC, Eklof BG, Gillespie DL Gloviczki ML, Lohr JM, McLafferty RB, Meissner MH, Murad MH, et al: The care of patients with varicose veins and associated chronic venous diseases: Clinical practice guidelines of the Society for Vascular Surgery and the American Venous Forum. J Vasc Surg 53 (5 Suppl): 2S-48S, 2011.

9. Proebstle TM, Alm J, Dimitri S, Rasmussen L, Whiteley M, Lawson J, Cher D and Davies A: The European multicenter cohort study on cyanoacrylate embolization of refluxing great saphenous veins. J Vasc Surg Venous Lymphat Disord 3: 2-7, 2015.

10. Geier B, Stucker M, Hummel T, Burger P, Frings N, Hartmann M, Stenger D, Schwahn-Schreiber C, Schonath M and Mumme A: Residual stumps associated with inguinal varicose vein recurrences: A multicenter study. Eur J Vasc Endovasc Surg 36: 207-210, 2008.

11. Kim J, Cho S, Joh JH, Ahn HJ and Park HC: Effect of diameter of saphenous vein on stump length after radiofrequency ablation for varicose vein. Vasc Specialist Int 31: 125-129, 2015.

12. Joh JH, Kim WS, Jung IM, Park KH, Lee T, Kang JM and Consensus Working Group: Consensus for the treatment of varicose vein with radiofrequency ablation. Vasc Specialist Int 30: 105-112, 2014.

13. Harlander-Locke M, Jimenez JC, Lawrence PF, Derubertis BG, Rigberg DA, Gelabert HA and Farley SM: Management of endovenous heat-induced thrombus using a classification system and treatment algorithm following segmental thermal ablation of the small saphenous vein. J Vasc Surg 58: 427-431, 2013.

14. Chan YC, Law Y, Cheung GC and Cheng SW: Predictors of recanalization for incompetent great saphenous veins treated with cyanoacrylate glue. J Vasc Interv Radiol 28: 665-671, 2017.

15. Almeida JI, Javier JJ, Mackay E, Bautista C and Proebstle TM: First human use of cyanoacrylate adhesive for treatment of saphenous vein incompetence. J Vasc Surg Venous Lymphat Disord 1: 174-180, 2013

16. Aalto-Korte K, Alanko K, Kuuliala O and Jolanki R: Occupational methacrylate and acrylate allergy from glues. Contact Dermatitis 58: 340-346, 2008.

17. Quinn JC, Mittal N, Baisre A, Cho ES, Sharer LR, Gandhi C and Prestigiacomo CJ: Vascular inflammation with eosinophils after the use of n-butyl cyanoacrylate liquid embolic system. J Neurointerv Surg 3: 21-24, 2011.

18. Tekin Aİ, Tuncer ON, Memetoğlu ME, Arslan Ü, Öztekin A, Yağmur B, Biçer M and Özmen R: Nonthermal, nontumescent endovenous treatment of varicose veins. Ann Vasc Surg 36: 231-235, 2016.

19. Koramaz I, El Kılıç H, Gökalp F, Bitargil M, Bektaş N, Engin E, Egici MT and Bozkurt AK: Ablation of the great saphenous vein with nontumescent n-butyl cyanoacrylate versus endovenous laser therapy. J Vasc Surg Venous Lymphat Disord 5: 210-215, 2017. 